\title{
RANCANG BANGUN (SISTEM INFORMASI E-LEARNING BERBASIS WEB PADA SMK DAARUT TAUFIQ TANGERANG
}

\author{
Eka Wulansari Fridayanthie ${ }^{1}$, Mochammad Abdul Azis $^{2}$, Aliffah Kusumaningrum ${ }^{3}$ \\ AMIK BSI Tangerang ${ }^{123}$ \\ Jl. Gatot Subroto No. 8 Tangerang
}

eka.ewf@bsi.ac.id, mochabdulazis01@gmail.com, aliffah.akg@bsi.ac.id

\begin{abstract}
ABSTRAKSI
Selama ini semua proses pembelajaran di SMK Daarut Taufiq Tangerang masih bersifat konveksional, dengan kata lain bahwa proses belajar mengajar antara siswa dengan guru hanya dapat dilakukan dengan syarat terjadinya pertemuan antara siswa dengan guru di dalam kelas. Jika pertemuan antara siswa dengan guru tidak terjadi atau guru yang bersangkutan tidak hadir dan waktu pembelajaran yang dibatasi pihak sekolah $\mathrm{m}$ maka secara otomatis proses pembelajaran pun akan terhambat. Untuk merancang aplikasi ini digunakan metode pererancangan struktural yaitu pembuatan Entity Relationship Diagram (ERD) dan pembuatan Logical Relationship Structure (LRS) untuk merancang dan mendokumentasikan sistem perangkat lunak berdasarkan aliran data. Dengan adanya e-learning ini dapat membantu proses belajar mengajaran agar lebih optimal. Memudahkan para guru untuk dapat mendistribusikan materi pelajaran untuk siswa/i di SMK Daarut Taufiq Tangerang dn juga siswa/i dapat dengan mudah mendapat materi pelajaran.
\end{abstract}

Kata Kunci: SMK Daarut Taufiq Tangerang, E-learning

\begin{abstract}
So far, all learning process in SMK Daarut Taufiq Tangerang is still convective, in other words, that the teaching and learning process between students and teachers can only be done on the condition of meeting between students with teachers in the classroom. If the meeting between students and teachers does not occur or the teacher is not present and the learning time is limited by the school $m$ then automatically the learning process will be hampered. To design this application used structural design method that is making Entity Relationship Diagram (ERD) and making Logical Relationship Structure (LRS) to design and documenting software system based on data flow. With this e-learning can help the teaching-learning process to be more optimal. Facilitate the teachers to be able to distribute the subject matter for students in SMK Daarut Taufiq Tangerang in also students / I can easily get the subject matter.
\end{abstract}

Keywords: SMK Daarut Taufiq Tangerang, E-learning

\section{PENDAHULUAN}

Perkembangan teknologi informasi dalam bidang pendidikan khususnya SMK Daarut Taufiq Tangerang memanfaatkan eLearning untuk meningkatkan efektivitas dan fleksibilitas pembelajaran karna SMK Daarut Taufiq Tangerang masih bersifat konvensional, dengan kata lain bahwa proses belajar mengajar antara siswa dengan guru hanya dapat dilakukan dengan syarat terjadinya pertemuan antara siswa dengan guru di dalam kelas. Jika pertemuan antara siswa dengan guru tidak terjadi atau guru yang bersangkutan tidak hadir dan siswa yang menjalani PKL (Praktek Kerja Lapangan), maka secara otomatis proses pembelajaran pun akan terhambat dan terbatasnya waktu belajar mengajar dikelas terkadang menghalangi para guru dalam memberikan semua materi pelajaran kepada siswa-siswi. Hal ini menjadi masalah tersendiri untuk siswa-siswi dan guru yang ingin menyampaikan secara detail tentang mata pelajaran tersebut.

Salah satu cara yang bisa ditempuh untuk mengatasi persoalan diatas adalah perlu adanya metode belajar mengajar yang dapat di guanakan oleh guru dan siswa sebagai media pembelajar yang baik yang bersifat online.

Dalam sistem ini materi dapat di update dengan mudah sehingga mampu mengantisipasi kekurangan materi terhadap siswanya yang melakukan proses PKL ataupun guru yang berhalangan hadir, siswa dan guru pun dapat mengakses sistem ini dengan mudah setiap waktu sehingga memudahkan aktifitas belajar dimanapun.

"E-learning memiliki manfaat bagi lembaga pendidikan untuk menarik lebih banyak 
peserta didik dibanding metode pembelajaran konvensional. E-learning tidak hanya dapat meningkatkan jumlah peserta didik yang ingin mendaftar saja, namun juga memberikan kesempatan peserta didik yang sebelumnya dinyatakan tidak akan mampu mengikuti pendidikan menjadi dapat melakukannya." (Noor, 2017).

"E-learning berisi materi pelajaran yang disampaikan oleh pengajar kepada siswa dan siswa dapat mendownloadnya dengan format PDF dan Document, melihat teman satu kelas, melihat mata pelajaran dan mengerjakan tugas atau quis. Materi pelajaran dan tugas atau kuis yang ada di dalam sistem e-learning dapat disesuaikan dengan kelas yang diduduki." (Sihotang, 2017)

Salah satu metode pengembangan perangkat lunak (System Development Life Cycle) adalah dengan model waterfall atau lebih dikenal dengan model linear sequential, yang merupakan model klasik bersifat sistematis, yang digunakan sebagai acuan dalam mengembangkan suatu proyek yang inovatif dan kompleks. Model waterfall "Model SDLC air terjun(waterfall) sering juga disebut model sekuinsial linier (sequintal linear) atau alur hidup klasik (classic life cycle). Model air terjun menyediakan pendekatan alur hidup perangkat lunak secara sekuensial atau terurut dari analisis, desain, pengodean, pengujian dan tahap pendukung(support)" (Shalahudin, 2015)

\section{METODE PENELITIAN}

Metode penelitian yang digunakan penulis untuk mendapatkan data sebagai objek penulisan, yaitu :

\subsection{Observasi (obserbatoin)}

Dengan melakukan pengamatan scara langsung terhadap pembuatan aplikasi yang menjelaskan alur program e-learning.

\subsection{Wawancara (interview)}

Wawancara yaitu dengan cara berkonsultasi atau bertanya langsung dengan beberapa guru dan siswa.

\subsection{Studi Pustaka (library research)}

Pengumpulan data dilakukan denga cara mengumpulkan literatur, jurnal, paper dan bacaan-bacaan yang diangkat menjadi referensi

Metode yang digunakan pada pengembangan perangkat lunak ini menggunakan model waterfall yang terbagi menjadi 5 tahapan (Shalahudin, 2015) yaitu:
1. Analisis Kebutuhan Perangkat Lunak Proses pengumpulan kebutuhan dilakukan secara intensif untuk mespesifikasikan kebutuhan perangkat lunak agar dapat dipahami perangkat lunak seperti apa yang dibutuhkan oleh user. Spesifikasi kebutuhan perangkat lunak pada tahap ini perlu untuk didokumentasikan.

2. Desain

Desain perangkat lunak adalah proses multi langkah yang fokus pada desain pembuatan program perangkat lunak termasuk stuktur data, arsitektur perangkat lunak, representasi antarmuka, dan prosedur pengodean. Tahap ini mentralasi kebutuhan perangkat lunak dari tahap analisis kebutuhan ke representasi dessain agar dapat diimplementasikan menjadi program pada tahap selanjutnya. Desain perangkat lunak yang dihasilkan pada tahap ini juga perlu didokumentasikan.

3. Pembuatan Kode Program

Desain harus ditranlasikan ke dalam program perangkat lunak. Hasil dari tahap ini adalah program komputer sesuai dengan desain yang telah dibuat pada tahap desain.

4. Pengujian

Pengujian fokus pada perangkat lunak secara dari segi logik dan fungsional dan memastikan bahwa semua bagian sudah diuji. Hal ini dilakukan untuk meminimalisir kesalahan (error) dan memastikan keluaran yang dihasilkan sesuai dengan yang diinginkan.

5. Pendukung (support)

Tidak menutup kemungkinan sebuah perangkat lunak mengalami perubahan ketika sudah dikirimkan ke user. Perubahan bisa terjadi karena adanya kesalahan yang muncul dan tidak terdeteksi saat pengujian atau perangkat lunak yang harus beradaptasi dengan lingkungan baru.

\section{PEMBAHASAN}

\subsection{Analisa Kebutuhan Sistem}

Sistem informasi e-learning berbasis web merupakan program usulan untuk mempermudah pihak sekolah seperti anatara guru dan siswa dalam melakukan kegiatan belajar-mengajar, maupun melihat data nilai akademik sekolah. Berikut ini spesifikasi 
kebutuhan dari sistem aplikasi pembelajaran online berbasis web.

1. Skenario Kebutuhan Admin :

a. Admin dapat menglola Gallery.

b. Admin dapat menglola halaman berita.

c. Admin dapat menglola halaman profil.

d. Admin dapat menglola data Guru.

e. Admin dapat menglola data Siswa.

f. Admin dapat menglola Kelas.

g. Admin dapat mengelola mata pelajaran.

h. Admin dapat mengelola jadwal mengajar

i. Melakukan Logout.

2. Skenario Kebutuhan Guru :

a. Guru bisa membuat materi-materi yang akan diberikan kepada murid.

b. Guru bisa membuat tugas untuk para murid

c. Guru bisa melihat nilai dari siswa.

d. Guru bisa merubah data guru.

3. Skenario Kebutuhan Siswa :

a. Siswa bisa medownload materi yang di buat oleh guru.

b. Siswa bisa mengerjakan tugas yang telah diberikan oleh guru.

c. Siswa bisa melihat nilai dari hasil tugas yang di kerjakan.

d. Siswa bisa melihat jadwal mata pelajaran.

e. Siswa bisa merubah data nya.

\subsection{DESAIN}

4.2.1. Rancangan Basis Data

1. $\operatorname{ERD~(Entity~Relationship~Diagram)~}$

Pada rancangan sistem informasi $E$ Learning berbasis web

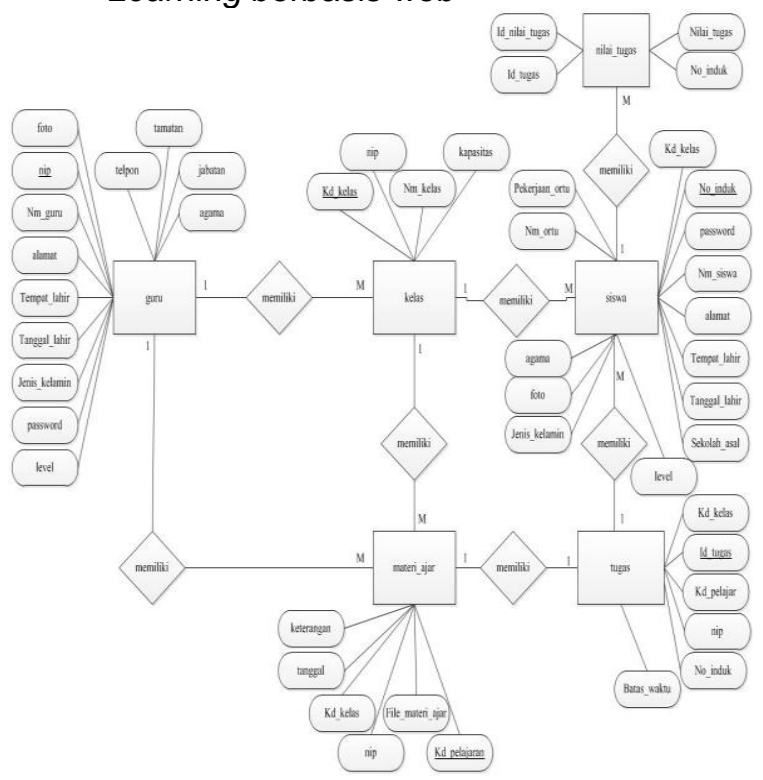

Sumber : Hasil Penelitian (2018)

Gambar 1. Entity Relationship Diagram
2. Logical Record Structured (LRS) pada Rancangan Sistem informasi $E$ -

Learning berbasis web

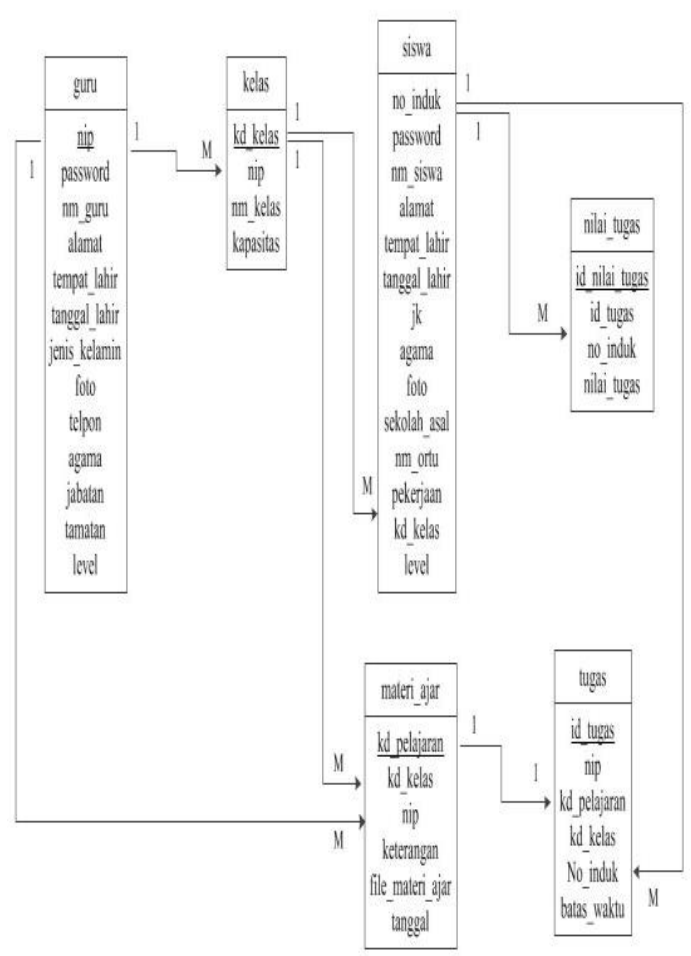

Sumber : Hasil Penelitian (2018)

Gambar 2. Logical Record Structured

\subsubsection{Tampilan Antar Muka}

Design interface pada website SMK Daarut Taufiq Kemiri Kabupaten Tangerang terdiri dari 4 halaman yaitu halaman utama, halaman admin, halaman guru, halaman siswa

1.

1. Tampilan Halaman Pengunjung

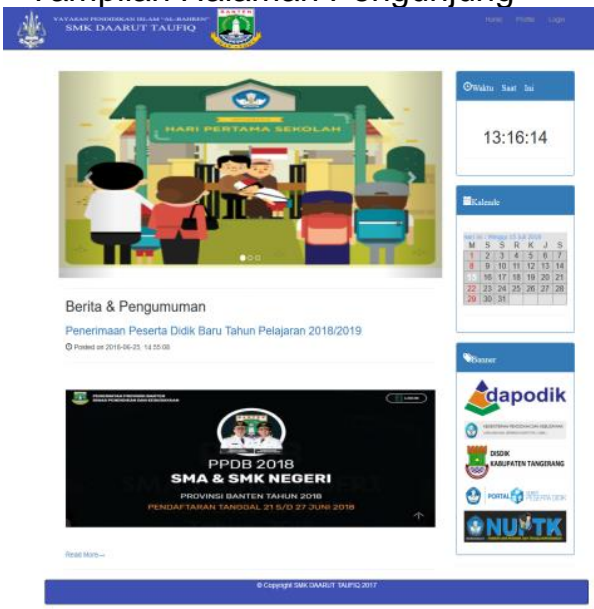

Sumber : Hasil Penelitian (2018)

Gambar 3. Tampilan Halaman Pengunjung

2. Tampilan Halaman Login 
Silahkan Login melalui Form Berikut

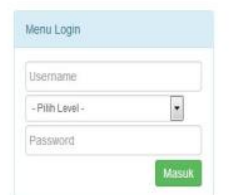

Sumber : Hasil Penelitian (2018)

Gambar 4. Tampilan Halaman Login

3. Tampilan Halaman Admin

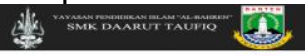
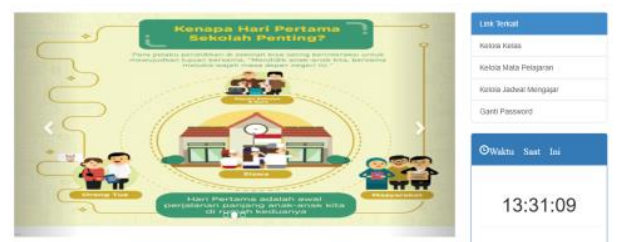

13:31:09

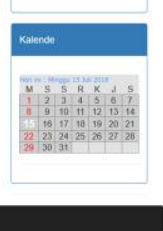

Sumber : Hasil Penelitian (2018)

Gambar 5. Tampilan Halaman Admin

4. Tampilan Halaman Kelola Siswa

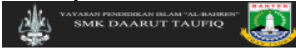
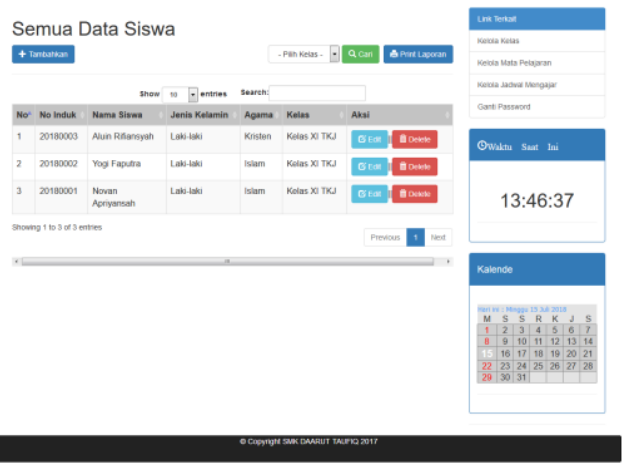

Sumber : Hasil Penelitian (2018)

Gambar 6. Tampilan Halaman Kelola Siswa

5. Halaman Kelola Jadwal Pelajaran

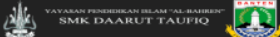
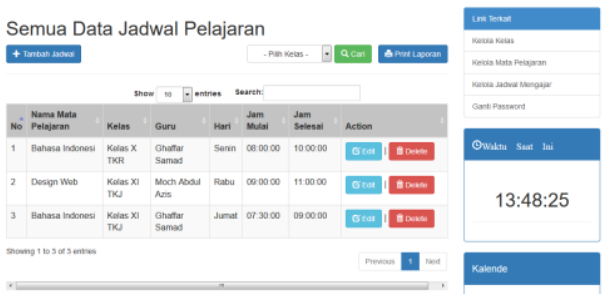

Sumber : Hasil Penelitian (2018)

Gambar 7. Halaman Jadwal Pelajaran

\subsection{Software Architecture}

A. Component Diagram

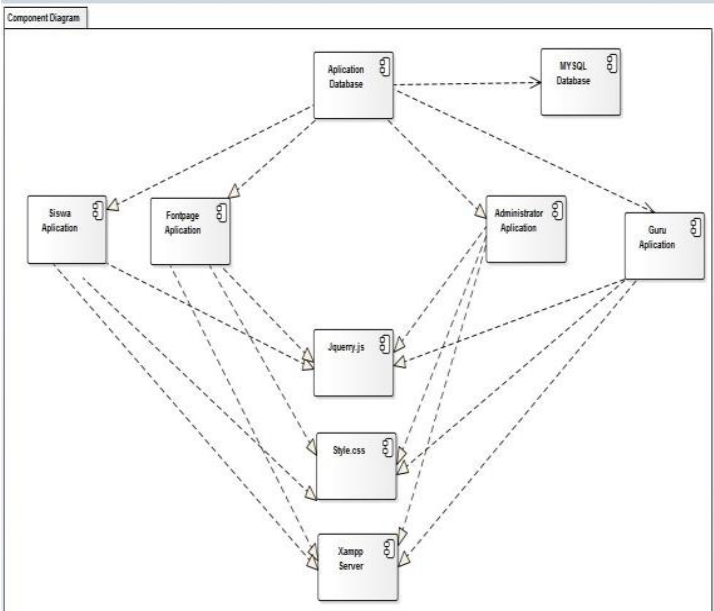

Sumber : Hasil Penelitian (2018)

Gambar 8. Component Diagram

B. Deployment Diagram

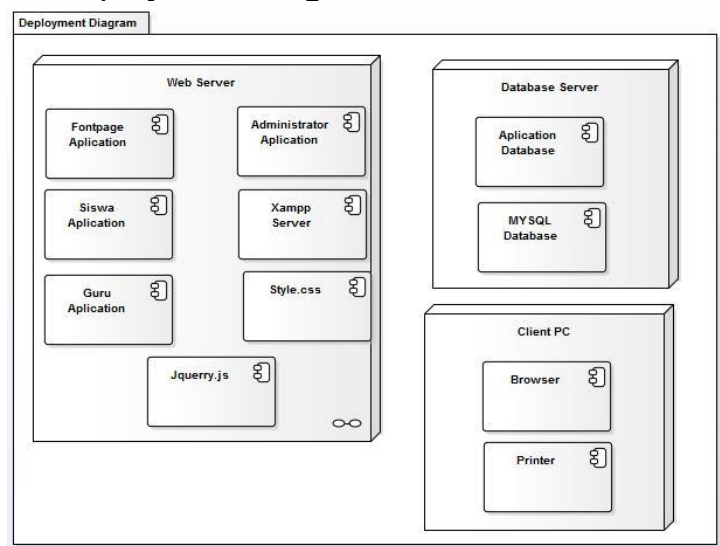

Sumber : Hasil Penelitian (2018)

Gambar 9. Deployment Diagram

\subsection{PENGUJIAN}

Menurut Rosa dan Shalahuddin (2013:275276) Black-box testing adalah "Perangkat lunak dari segi spesifikasi fungsional tanpa menguji desain dan kode program".

Tabel 1.Hasil Pengujian Black Box testing Halaman Login 


\begin{tabular}{|l|l|l|l|l|l|}
\hline No & Skenario Pengujian & Test Case & Hasil Yang diharapkan & Hasil Pengujian & Kesimpulan \\
\hline 1 & $\begin{array}{l}\text { Username,Level dan } \\
\text { Password Diisi } \\
\text { dengan salah } \\
\text { kemudian } \\
\text { klik tombol masulk }\end{array}$ & $\begin{array}{l}\text { Username: } \\
\text { (Salah) } \\
\text { Level: } \\
\text { (Salah) } \\
\text { Password: } \\
\text { (Salah) }\end{array}$ & $\begin{array}{l}\text { Sistem akan menolak } \\
\text { akses user dan } \\
\text { menampilkan } \\
\text { "Maaf, Anda Gagal } \\
\text { Login" }\end{array}$ & Sesuai Harapan & Valid \\
\hline 2 & $\begin{array}{l}\text { MengetikUsername } \\
\text { benar dan level } \\
\text { Password diisi } \\
\text { dengan salah } \\
\text { kemudian } \\
\text { klik tombol masuk }\end{array}$ & $\begin{array}{l}\text { Username: } \\
\text { (Benar) } \\
\text { Level: } \\
\text { (Salah) } \\
\text { Password: } \\
\text { (Salah) }\end{array}$ & $\begin{array}{l}\text { Sistem akan menolak } \\
\text { akses user dan } \\
\text { menampilkan } \\
\text { "Maaf, Anda Gagal } \\
\text { Login" Sesuai Harapan }\end{array}$ & Valid \\
\hline 3 & $\begin{array}{l}\text { MengetikUsername } \\
\text { dan level benar dan } \\
\text { Password diisi } \\
\text { dengan salah } \\
\text { kemudian } \\
\text { klik tombol masuk }\end{array}$ & $\begin{array}{l}\text { Username: } \\
\text { (Benar) } \\
\text { Level: } \\
\text { (Benar) } \\
\text { Password: } \\
\text { (Salah) }\end{array}$ & $\begin{array}{l}\text { Sistem akan menolak } \\
\text { akses user dan } \\
\text { menampilkan } \\
\text { "Maaf, Anda Gagal } \\
\text { Login" }\end{array}$ & Sesuai Harapan & Valid \\
\hline 4 & $\begin{array}{l}\text { MengetikUsername, } \\
\text { level dan password } \\
\text { benar kemudian } \\
\text { klik tombol masuk }\end{array}$ & $\begin{array}{l}\text { Username: } \\
\text { (Benar) } \\
\text { Level: } \\
\text { (Benar) } \\
\text { Password: } \\
\text { (Benar) }\end{array}$ & $\begin{array}{l}\text { Sistem akan menerima } \\
\text { akses login dan } \\
\text { kemudian lansung } \\
\text { menampilkan halaman } \\
\text { utama }\end{array}$ & Sesuai Harapan & Valid \\
\hline
\end{tabular}

Sumber : Hasil Penelitian (2018)

\section{PENUTUP}

Berdasarkan dari bahasan sebelumnya, maka penulis dapat mengambil kesimpulan sebagai berikut: Dengan adanya website $e$ learning SMK Daarut Taufiq ini maka siswa dapat mengakses materi yang diberikan oleh guru kapan saja. Siswa dapat mengerjakan kuis untuk mendapatkan nilai tambahan. Keterbatasan ruang dan waktu dapat diatasi dengan adanya sistem e-learning pada SMK Daarut Taufiq.

Website e-learning SMK Daarut Taufiq ini merupakan website yang masih cukup sederhana. Penulis mengharapkan agar situs ini bisa dikembangkan menjadi situs yang lebih interaktif dengan user dan dengan tampilan yang lebih menarik dengan menumenu yang lebih bervariasi lagi. Oleh karena itu penulis memberikan beberapa saran, anatara lain: Dalam rangka meningkatkan mutu pendidikan pada SMK Daarut Taufiq Tangerang maka perlu dikembangkan lagi metode-metode pembelajaran interaktif lainnya untuk meningkatkan minat belajar para siswa. Untuk meningkatkan kinerja serta untuk mengembangkan website ini maka sebaiknya diadakan pengembangan website mulai dari tampilan halaman web sampai dengan maintenance. Dalam perancangan website ini masih sederhana dalam hal fitur-fitur yang ditawarkan. Diharapkan untuk mempunyai backup file untuk mencegah apabila terjadi kesalahan dalam rancangan website.
DAFTAR PUSTAKA

Anhar. (2010). Panduang Menguasai PHP \& MySQL Secara Otodidak. Jakarta: Media Kita.

Noor, M. H. (2017). Penggunaan E-Learning dalam pembelajaran berbasis proyek di SMA Negeri 1 Jepara. Innovative Journal of Curriculum and Educational Technology, 17-26.

Shalahudin, R. d. (2015). Rekayasa Perangkat Lunak Terstruktur dan Berorientasi Objek. Bandung: Informatika.

Sigit, A. (2011). Website Super Canggih Dengan Plufin Jquery Terbaik. Yogyakarta: Media Kita.

Sihotang. (2017). Pembuatan Aplikasi ELearning Pada SMK Swasta. Jakarta: Informatika. 